BNL-113454-2017-JA

\title{
Amazon boundary layer aerosol concentration sustained by vertical transport during rainfall
}

Jian Wang, Radovan Krejci, Scott Giangrande, Chongai Kuang, Henrique M. J. Barbosa, Joel Brito, Samara Carbone, Xuguang Chi, Jennifer Comstock, Florian Ditas, Jost Lavric, Hanna E. Manninen, Fan Mei, Daniel Moran-Zuloaga, Christopher Pöhlker, Mira L. Pöhlker, Jorge Saturno, Beat Schmid, Rodrigo A. F. Souza, Stephen R. Springston, Jason M. Tomlinson, Tami Toto, David Walter, Daniela Wimmer, James N. Smith, Markku Kulmala, Luiz A. T. Machado, Paulo Artaxo, Meinrat O. Andreae, Tuukka Petäjä \& Scot T. Martin

Accepted for publication in Nature

November 2016

Environmental \& Climate Science Dept.

Brookhaven National Laboratory

U.S. Department of Energy
USDOE Office of Science (SC),
Biological and Environmental Research (BER) (SC-23)

Notice: This manuscript has been authored by employees of Brookhaven Science Associates, LLC under Contract No. DE-SC0012704 with the U.S. Department of Energy. The publisher by accepting the manuscript for publication acknowledges that the United States Government retains a non-exclusive, paid-up, irrevocable, world-wide license to publish or reproduce the published form of this manuscript, or allow others to do so, for United States Government purposes. 


\section{DISCLAIMER}

This report was prepared as an account of work sponsored by an agency of the United States Government. Neither the United States Government nor any agency thereof, nor any of their employees, nor any of their contractors, subcontractors, or their employees, makes any warranty, express or implied, or assumes any legal liability or responsibility for the accuracy, completeness, or any third party's use or the results of such use of any information, apparatus, product, or process disclosed, or represents that its use would not infringe privately owned rights. Reference herein to any specific commercial product, process, or service by trade name, trademark, manufacturer, or otherwise, does not necessarily constitute or imply its endorsement, recommendation, or favoring by the United States Government or any agency thereof or its contractors or subcontractors. The views and opinions of authors expressed herein do not necessarily state or reflect those of the United States Government or any agency thereof. 


\section{Amazon boundary layer aerosol concentration sustained by vertical transport during rainfall}

Jian Wang ${ }^{1}$, Radovan Krejci² ${ }^{2}$ Scott Giangrande ${ }^{1}$, Chongai Kuang ${ }^{1}$, Henrique M. J. Barbosa ${ }^{3}$, Joel Brito ${ }^{3}$, Samara Carbone ${ }^{3}$, Xuguang Chi ${ }^{4,5}$, Jennifer Comstock ${ }^{6}$, Florian Ditas ${ }^{4}$, Jost Lavric ${ }^{7}$, Hanna E. Manninen ${ }^{8}$, Fan Mei ${ }^{6}$, Daniel Moran-Zuloaga ${ }^{4}$, Christopher Pöhlker ${ }^{4}$, Mira L. Pöhlker ${ }^{4}$, Jorge Saturno ${ }^{4}$, Beat Schmid ${ }^{6}$, Rodrigo A. F. Souza ${ }^{9}$, Stephen R. Springston ${ }^{1}$, Jason M. Tomlinson ${ }^{6}$, Tami Toto ${ }^{1}$, David Walter ${ }^{4}$, Daniela Wimmer ${ }^{8}$, James N. Smith ${ }^{10}$, Markku Kulmala ${ }^{8}$, Luiz A. T. Machado ${ }^{11}$, Paulo Artaxo ${ }^{3}$, Meinrat O. Andreae ${ }^{4,12}$, Tuukka Petäjä ${ }^{8} \&$ Scot T. Martin ${ }^{13}$

The nucleation of atmospheric vapours is an important source of new aerosol particles that can subsequently grow to form cloud condensation nuclei in the atmosphere ${ }^{1}$. Most field studies of atmospheric aerosols over continents are influenced by atmospheric vapours of anthropogenic origin (for example, ref. 2) and, in consequence, aerosol processes in pristine, terrestrial environments remain poorly understood. The Amazon rainforest is one of the few continental regions where aerosol particles and their precursors can be studied under near-natural conditions ${ }^{3-5}$, but the origin of small aerosol particles that grow into cloud condensation nuclei in the Amazon boundary layer remains unclear ${ }^{6-8}$. Here we present aircraft- and ground-based measurements under clean conditions during the wet season in the central Amazon basin. We find that high concentrations of small aerosol particles (with diameters of less than 50 nanometres) in the lower free troposphere are transported from the free troposphere into the boundary layer during precipitation events by strong convective downdrafts and weaker downward motions in the trailing stratiform region. This rapid vertical transport can help to maintain the population of particles in the pristine Amazon boundary layer, and may therefore influence cloud properties and climate under natural conditions.

Comprehensive characterizations of aerosols and trace gases were carried out onboard the US Department of Energy Gulfstream-1 (G-1) research aircraft and at several surface sites, during the Observations and Modelling of the Green Ocean Amazon (GoAmazon2014/5) experiment near Manaus, Amazonas, Brazil $\left(3.1^{\circ} \mathrm{S}, 60.0^{\circ} \mathrm{W}\right)$, in the central Amazon basin ${ }^{9}$. The pollution plume of Manaus, a city of about two million people, generally follows the north-easterly trade winds. The present analysis focuses on measurements under clean conditions during the wet season in March 2014 onboard G-1 and from March to May 2014 at the T0a surface site (Amazon Tall Tower Observatory, ATTO $^{10}$ ) located $150 \mathrm{~km}$ northeast of Manaus (Extended Data Fig. 1). Air masses arriving at T0a during the wet season are typically brought by the north-easterly trade winds and travel across at least $1,000 \mathrm{~km}$ of undeveloped tropical rainforest, and are therefore generally clean (Extended Data Fig. 2). Some analysis was also conducted using datasets from the T3 site ( $70 \mathrm{~km}$ west of Manaus). Air masses arriving at T3 were clean or polluted depending on the direction of the Manaus pollution plume.

We observed a strong vertical gradient in the particle size spectrum above central Amazonia under clean conditions. Figure 1a shows the size spectra measured upwind of Manaus at five altitudes between $650 \mathrm{~m}$ and 5,800 $\mathrm{m}$ (above mean sea level) from 13:18 to 14:42 (all times are in UTC) on 7 March 2014. Altitudes of 3,200 m, 4,500 m and $5800 \mathrm{~m}$ were within the free troposphere, as indicated by the equivalent potential temperature $\left(\theta_{\mathrm{e}}\right)$. At $5,800 \mathrm{~m}$, the spectrum was dominated by an Aitken mode of $40 \mathrm{~nm}$ diameter. These particles can arise from new particle formation in the outflow of deep convective systems ${ }^{11-13}$, in which the particle surface area is low owing to wet scavenging of existing particles and the ambient temperature is low, facilitating the formation of particles of a few nanometres from gas-phase precursors through several potential mechanisms ${ }^{12,14-18}$. Condensational and coagulational growth of the nucleated particles between the points of formation and airborne observations can lead to the observed size spectrum ${ }^{13}$.

The elevated concentration of Aitken-mode particles at high altitude led to a strong vertical gradient in the particle number concentration between the free troposphere and the atmospheric boundary layer. As altitude decreased, the spectrum shifted towards larger particle sizes, as evidenced by the increase in the volume-average particle diameter (Fig. 1b). At the lowest altitude $(650 \mathrm{~m})$, which was inside the boundary layer, we found a pronounced increase in the concentration of particles with diameters greater than $100 \mathrm{~nm}$-at this size the particles are sufficiently large to serve as cloud condensation nuclei (CCN) under typical atmospheric conditions. The G-1 sampled particles in the free troposphere during four flights, all of which showed trends similar to that represented in Fig. 1 (Extended Data Fig. 3). The size spectra observed in both the lower free troposphere and the boundary layer are very similar to those reported earlier over the coastal region of the Amazon rainforest in Suriname ${ }^{19}$, suggesting that the observed vertical gradient is generally representative over Amazonia.

In many other environments, new particle formation in the boundary layer is one of the main processes producing small particles that subsequently grow and become CCN. In Amazonia, however, new particle formation has almost never been observed in the boundary layer under natural conditions ${ }^{3,20,21}$. Given the high number concentrations of Aitken particles at high altitudes, transport from the free troposphere can serve as an important source of small particles into the boundary layer. Once in the boundary layer, the atmospheric oxidation of biogenic volatile organic compounds emitted by the forest contributes the mass required for particle growth to CCN sizes ${ }^{6-8,22-24}$. The general mechanism of particle transport from the free troposphere to the boundary layer has been previously reported over marine regions (that is, 'blue oceans' $)^{25-27}$. For blue oceans, vertical transport is believed to take place by continuous but slow entrainment through a strong

\footnotetext{
${ }^{1}$ Environmental and Climate Sciences Department, Brookhaven National Laboratory, Upton, New York 11973, USA. ${ }^{2}$ Department of Applied Environmental Science and Analytical Chemistry, Stockholm University, Stockholm 10691. Sweden. ${ }^{3}$ University of São Paulo, São Paulo 05508-900, Brazil. ${ }^{4}$ Biogeochemistry and Multiphase Chemistry Departments, Max Planck Institute for Chemistry, 55128 Mainz, Germany. ${ }^{5}$ School of Atmospheric Sciences, Nanjing University, and Collaborative Innovation Center for Climate Change, Jiangsu Province, 210023 , Nanjing, China. ${ }^{6}$ Atmospheric Sciences and Global Change Division, Pacific Northwest National Laboratory, Richland, Washington 99352, USA. ${ }^{7}$ Department of Biogeochemical Systems, Max Planck Institute for Biogeochemistry, 07745 Jena, Germany. ${ }^{8}$ Department of Physics, University of Helsinki, PO Box 64, Fl-00014 Helsinki, Finland. ${ }^{9}$ Amazonas State University, Amazonas 69050-020, Brazil. ${ }^{10}$ Department of Chemistry, University of California, Irvine, California 92697, USA. ${ }^{11}$ National Institute for Space Research, São José dos Campos, São Paulo 12227-010, Brazil. ${ }^{12}$ Scripps Institution of Oceanography, University of California San Diego, La Jolla, California 92093, USA. ${ }^{13}$ School of Engineering and Applied Sciences and Department of Earth and Planetary Sciences, Harvard University, Cambridge, Massachusetts 02138, USA.
} 

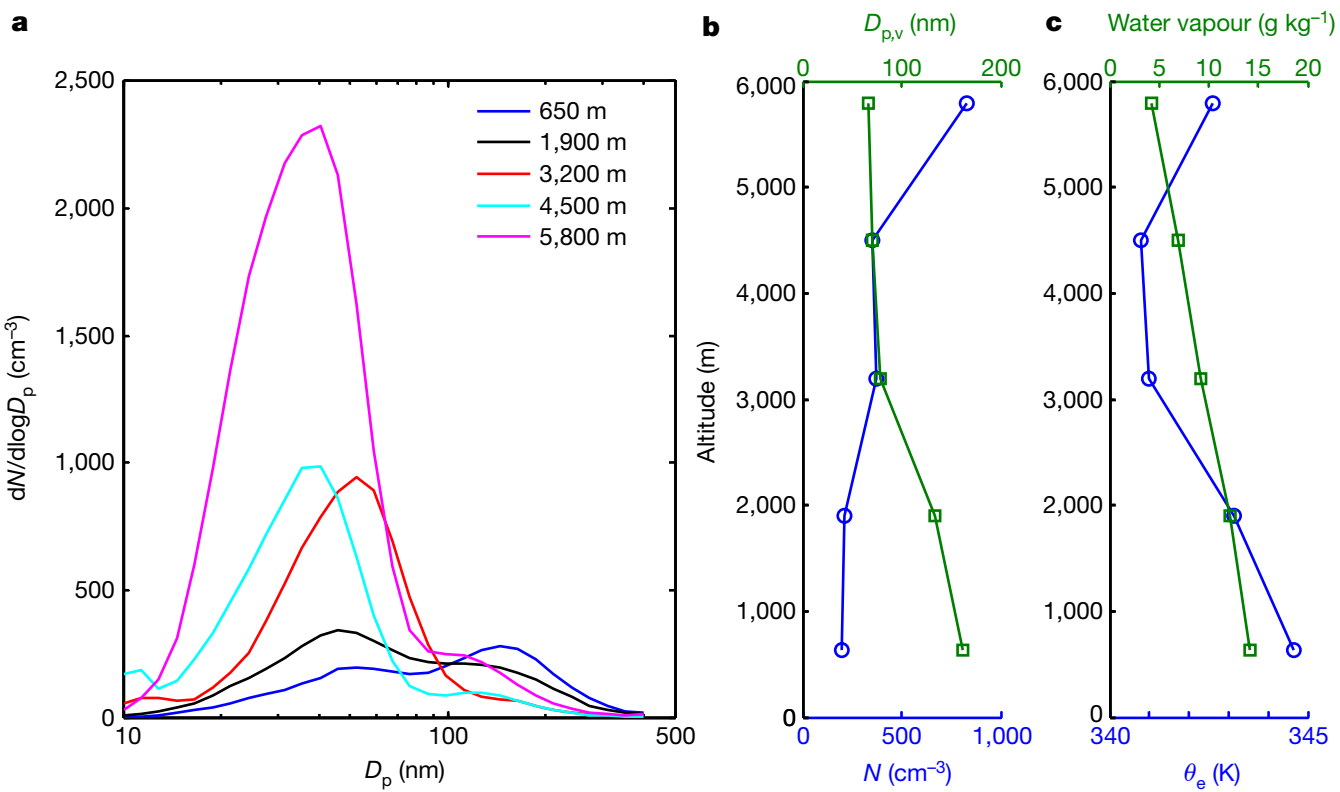

Figure 1 | Measurements made onboard the G-1 aircraft at five different altitudes upwind of Manaus on 7 March 2014. a, Particle size spectra normalized to standard temperature and pressure $(273.15 \mathrm{~K}$ and $101.325 \mathrm{kPa}$; STP). b, Particle number concentration $(N)$ normalized to STP and volume-average particle diameter $\left(D_{\mathrm{p}, \mathrm{v}}\right)$ derived from the size spectrum. c, Water vapour mixing ratio and equivalent potential temperature $\left(\theta_{\mathrm{e}}\right)$. The measurements are averaged over horizontal legs that were outside cloud or precipitation regions to avoid potential sampling artefacts. The quantities are averages of 324 to 3601 -s measurements that correspond to spatial scales ranging from $34 \mathrm{~km}$ to $40 \mathrm{~km}$.

size spectrum measured by G-1 in the free troposphere exhibited an Aitken mode with essentially the same mode diameter as observed at T0a following the precipitation event (Fig. 2d, Extended Data Fig. 3g). Moreover, the size spectrum measured at $625 \mathrm{~m}$ altitude within the boundary layer was consistent with that observed at T0a following the event (Fig. 2d).

In the following quantitative analysis, we focus on three particle classes: all particles, small particles with diameters less than $50 \mathrm{~nm}$, and particles with diameters greater than $100 \mathrm{~nm}$ that can act as CCN. The respective surface concentrations of these particle classes are denoted by $N, N_{<50}$ and $N_{>100}$. There was a strong increase in $N_{<50}$ following the strong convective precipitation and the stratiform rain, whereas $N_{>100}$ was substantially lower. The lack of nucleation-mode particles (that is, particles with diameters smaller than $20 \mathrm{~nm}$ ) and the sudden increase in the Aitken-mode particle concentration immediately following the precipitation indicate that the increase in $N_{<50}$ cannot be explained by new particle formation within the boundary layer. The decrease in $N_{>100}$ is attributed to low concentrations in the downward-transported free tropospheric air (Fig. 2d, Extended Data Fig. 3g) as well as efficient removal by precipitation scavenging. The total particle concentration following the precipitation event remained nearly the same as before, indicating that the removal of CCN by precipitation was compensated on a number basis by the increase in small particles from the free troposphere. An elevated $N_{<50}$ was observed in the majority of cases following major precipitation events during the wet season. Another example of the vertical transport observed at T0a on 4 May is shown in Extended Data Fig. 6.

The generalized role of vertical transport by downdrafts as a source of small particles into the atmospheric boundary layer was examined statistically using three months of measurements at T0a. As shown in Fig. 2b, the vertical transport of dry air leads to a pronounced decrease in $\theta_{\mathrm{e}}$ in the boundary layer. Although $\theta_{\mathrm{e}}$ was also influenced by other processes, such as solar heating, these processes had a strong and recognizable diel pattern (Extended Data Fig. 7a). The quantity $\Delta \theta_{\mathrm{e}}=\theta_{\mathrm{e}}^{\prime}-\overline{\theta_{\mathrm{e}}^{\prime}}$ was used as a surrogate for the extent of vertical transport of free tropospheric air, where $\bar{\theta}_{\mathrm{e}}^{\prime}$ is the diel average at the same time of day as $\theta_{\mathrm{e}}^{\prime}$, which represents seasonally detrended $\theta_{\mathrm{e}}$ (Extended Data Fig. 7b). trum had been when the system passed over T0a earlier. The particle 

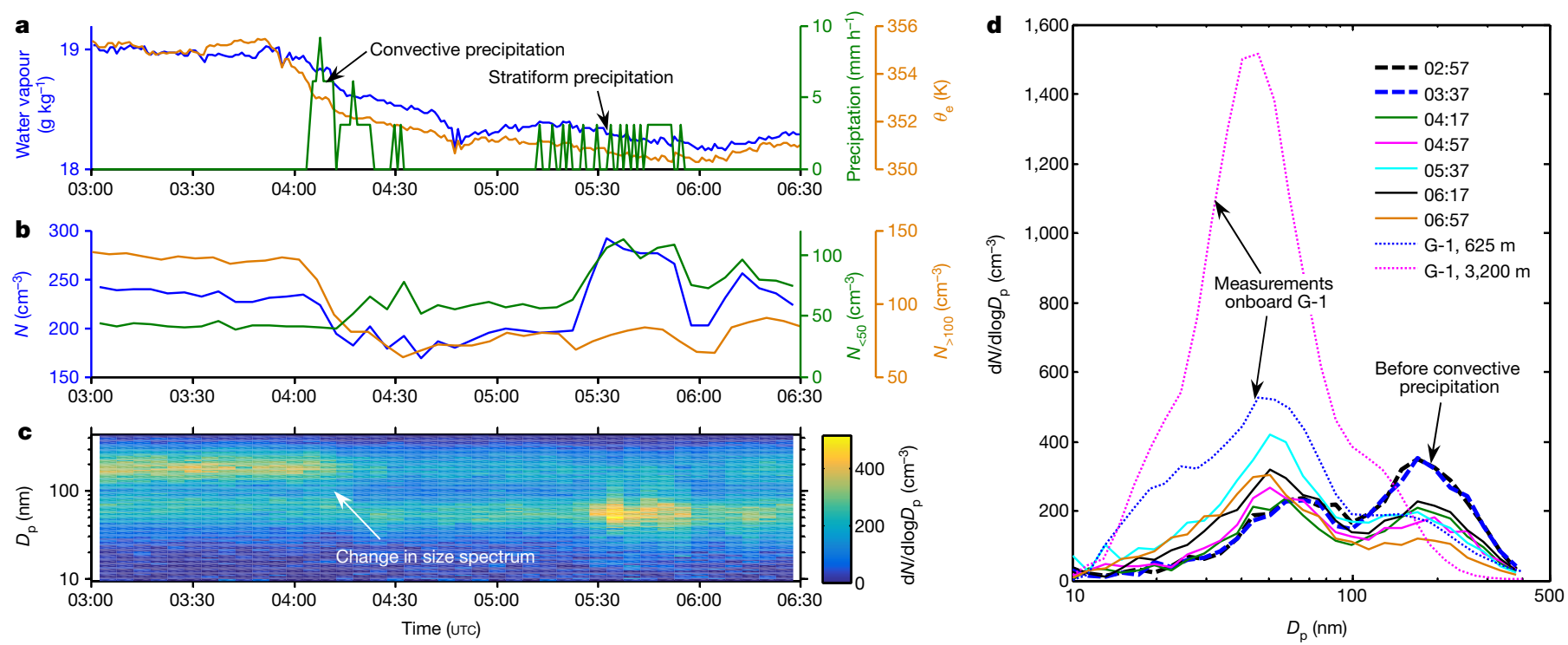

Figure 2 | The contribution of vertical transport of free tropospheric small particles to the particle concentration in the atmospheric boundary layer at T0a during a precipitation event on 19 March 2014. a, Water vapour mixing ratio, precipitation rate and equivalent potential temperature $\left(\theta_{\mathrm{e}}\right)$. b. The total particle number concentration $(N)$, the

A negative $\Delta \theta_{\mathrm{e}}$ value corresponds to a decrease in $\theta_{\mathrm{e}}$ due to mixing with free tropospheric air and is typically associated with precipitation (Extended Data Fig. 8). Positive $\Delta \theta_{e}$ values can arise from high instability (that is, convective available potential energy) as well as strong mass and humidity convergence before rainfall events ${ }^{29}$.

For measurements at T0a under near-natural conditions from 1 March to 31 May 2014, the data points were grouped into ten $\Delta \theta_{\mathrm{e}}$ bins. The statistics for $N_{<50}, N_{>100}$ and $N$ for each bin were examined as a function of $\Delta \theta_{\mathrm{e}}$ (Fig. 3). As $\Delta \theta_{\mathrm{e}}$ decreased, $N_{<50}$ increased from $35 \mathrm{~cm}^{-3}$ to $125 \mathrm{~cm}^{-3}$ (Fig. 3b), indicating that mixing with free tropospheric air increased the concentration of small particles. In contrast, $N_{>100}$ decreased with decreasing $\Delta \theta_{\mathrm{e}}$ (Fig. $3 \mathrm{c}$ ). $N$ varied little over a wide range of $\Delta \theta_{\mathrm{e}}$ values (Fig. $3 \mathrm{~d}$ ), suggesting statistically that the removal of $\mathrm{CCN}$ is largely compensated by the influx of small particles
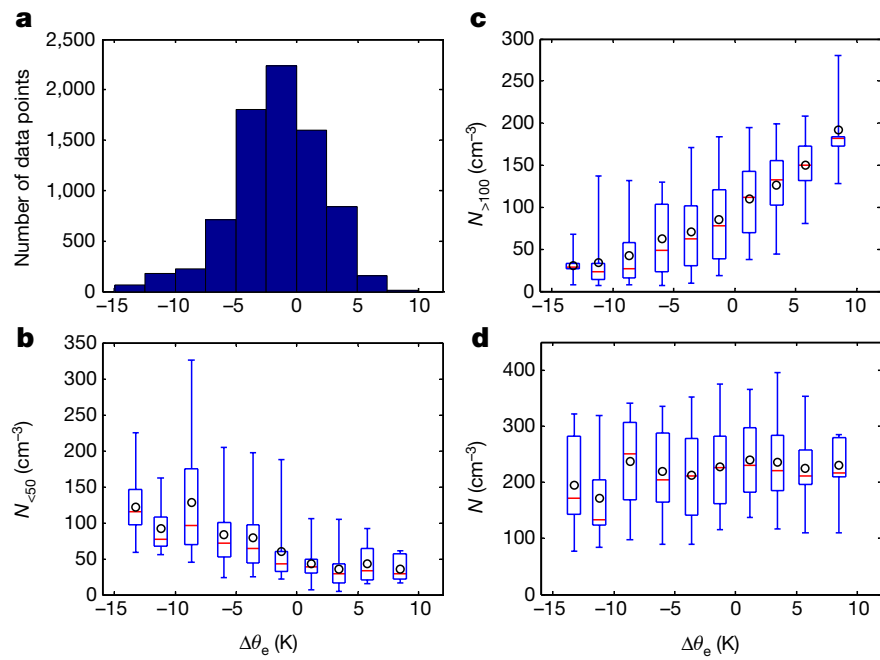

Figure 3 Variations in the particle number concentrations with $\Delta \theta_{\mathrm{e}}$. a, Number of data points for each $\Delta \theta_{\mathrm{e}}$ bin. b. Statistics of the small particle $\left(D_{\mathrm{p}}<50 \mathrm{~nm}\right)$ concentration for each $\Delta \theta_{\mathrm{e}}$ bin. $\mathbf{c}$, Statistics of the CCN-sized particle concentration $\left(D_{\mathrm{p}}>100 \mathrm{~nm}\right)$. d, Statistics of the total particle number concentration. The box and whisker plots are drawn for the 10th, 25th, 50th, 75th and 90th percentiles. The black circles represent the mean values. concentration of small particles with diameters $\left(D_{\mathrm{p}}\right)$ less than $50 \mathrm{~nm}\left(N_{<50}\right)$ and the concentration of $\mathrm{CCN}$-sized particles with diameters larger than $100 \mathrm{~nm}\left(N_{>100}\right)$. c, Particle size spectra $\left(\mathrm{d} N / \mathrm{d} \log D_{\mathrm{p}}\right)$ at ground level. d, Particle size spectra at ground level and those measured onboard G-1 on the same day.

transported from the free troposphere during precipitation. Given that precipitation scavenging is the main mechanism for the removal of CCN from the Amazon boundary layer, the similar $N$ values over the wide range of $\Delta \theta_{e}$ (that is, before and after precipitation) suggest that, in terms of particle number, the vertical transport of free tropospheric air is an important source that replenishes particles in the boundary layer and thereby maintains the climate-relevant $\mathrm{CCN}$ population, at least under natural conditions. In contrast, a similar analysis of measurements at the T3 site shows a much lower particle number concentration following precipitation events (that is, at lower $\Delta \theta_{\mathrm{e}}$ values) because, under polluted conditions, anthropogenic emissions are the main source replenishing boundary layer particles following precipitation (Extended Data Fig. 9). Complementary analysis of the T0a data was also carried out by removing the variations in $\theta_{\mathrm{e}}$ over timescales longer than $20 \mathrm{~h}$, including diel and seasonal variations, and using the filtered $\theta_{\mathrm{e}}$ as a proxy for the extent of vertical transport of free tropospheric air. The statistics of $N_{<50}, N_{>100}$ and $N$ were examined as a function of the filtered $\theta_{\mathrm{e}}$ values, and the results exhibit essentially the same features as shown in Fig. 3 (Extended Data Fig. 10). The particle number fluxes due to precipitation scavenging and vertical transport are estimated to be $3.9 \times 10^{11} \mathrm{~m}^{-2} \mathrm{~d}^{-1}$ and $3.1 \times 10^{11} \mathrm{~m}^{-2} \mathrm{~d}^{-1}$, respectively (details in Methods). Although future work is needed for a more accurate quantification, the estimate supports the finding that downward transport can largely compensate the precipitation scavenging of particles on a number basis.

In summary, the observations reported here show high concentrations of small particles in the lower free troposphere over the Amazon rainforest. We find that these particles arise from new particle formation in the outflow regions of deep convective systems, followed by condensational and coagulational growth. Under natural conditions, the small particles in the free troposphere become an important source of particles to the boundary layer through downward vertical transport, which occurs through rapid, sporadic downdrafts during convective precipitation events instead of the slow and continuous entrainment reported over marine regions. In the boundary layer, these particles grow and subsequently maintain the CCN population. An improved understanding of aerosol processes under natural conditions may help to reduce uncertainties in simulated climate change $e^{5,30}$. The vertical transport becomes a net sink of particles in the boundary layer under polluted conditions-such as those prevailing over most other tropical 
continental regions-when the boundary layer particle concentration exceeds that in the free troposphere.

Online Content Methods, along with any additional Extended Data display items and Source Data, are available in the online version of the paper; references unique to these sections appear only in the online paper.

\section{Received 5 October 2015; accepted 31 August 2016.}

Published online 24 October 2016.

1. Merikanto, J., Spracklen, D. V., Mann, G. W., Pickering, S. J. \& Carslaw, K. S Impact of nucleation on global CCN. Atmos. Chem. Phys. 9, 8601-8616 (2009).

2. Chi, X. et al. Long-term measurements of aerosol and carbon monoxide at the ZOTTO tall tower to characterize polluted and pristine air in the Siberian taiga. Atmos. Chem. Phys. 13, 12271-12298 (2013).

3. Martin, S. T. et al. Sources and properties of Amazonian aerosol particles. Rev. Geophys. 48, RG2002 (2010)

4. Artaxo, P. et al. Atmospheric aerosols in Amazonia and land use change: from natural biogenic to biomass burning conditions. Faraday Discuss. 165, 203-235 (2013)

5. Andreae, M. O. Aerosols before pollution. Science $\mathbf{3 1 5}, \mathbf{5 0 - 5 1}$ (2007)

6. Pöschl, U. et al. Rainforest aerosols as biogenic nuclei of clouds and precipitation in the Amazon. Science 329, 1513-1516 (2010).

7. Chen, Q. et al. Mass spectral characterization of submicron biogenic organic particles in the Amazon Basin. Geophys. Res. Lett. 36, L20806 (2009).

8. Pöhlker, C. et al. Biogenic potassium salt particles as seeds for secondary organic aerosol in the Amazon. Science 337, 1075-1078 (2012).

9. Martin, S. T. et al. Introduction: observations and modeling of the Green Ocean Amazon (GoAmazon2014/5). Atmos. Chem. Phys. 16, 4785-4797 (2016).

10. Andreae, M. O. et al. The Amazon Tall Tower Observatory (ATTO): overview of pilot measurements on ecosystem ecology, meteorology, trace gases, and aerosols. Atmos. Chem. Phys. 15, 10723-10776 (2015).

11. Clarke, A. D. et al. Particle production in the remote marine atmosphere: cloud outflow and subsidence during ACE 1. J. Geophys. Res. 103, 16397-16409 (1998).

12. Kulmala, M. et al. Deep convective clouds as aerosol production engines: role of insoluble organics. J. Geophys. Res. 111, D17202 (2006).

13. Krejci, R. et al. Evolution of aerosol properties over the rain forest in Surinam, South America, observed from aircraft during the LBA-CLAIRE 98 experiment. J. Geophys. Res. 108, 4561 (2003).

14. Clarke, A. D. et al. Nucleation in the equatorial free troposphere: favorable environments during PEM-Tropics. J. Geophys. Res. 104, 5735-5744 (1999).

15. Kirkby, J. et al. Role of sulphuric acid, ammonia and galactic cosmic rays in atmospheric aerosol nucleation. Nature 476, 429-433 (2011).

16. Lee, S. H. et al. Particle formation by ion nucleation in the upper troposphere and lower stratosphere. Science 301, 1886-1889 (2003).

17. Kulmala, M. et al. Direct observations of atmospheric aerosol nucleation. Science 339, 943-946 (2013)

18. Ekman, A. M. L. et al. Do organics contribute to small particle formation in the Amazonian upper troposphere? Geophys. Res. Lett. 35, L17810 (2008).

19. Krejci, R. et al. Spatial and temporal distribution of atmospheric aerosols in the lowermost troposphere over the Amazonian tropical rainforest. Atmos. Chem. Phys. 5, 1527-1543 (2005)

20. Spracklen, D. V. et al. The contribution of boundary layer nucleation events to total particle concentrations on regional and global scales. Atmos. Chem. Phys. 6, 5631-5648 (2006).

21. Zhou, J. C., Swietlicki, E., Hansson, H. C. \& Artaxo, P. Submicrometer aeroso particle size distribution and hygroscopic growth measured in the Amazon rain forest during the wet season. J. Geophys. Res. 107, 8055 (2002).

22. Claeys, M. et al. Formation of secondary organic aerosols through photooxidation of isoprene. Science 303, 1173-1176 (2004).
23. Chen, Q. et al. Submicron particle mass concentrations and sources in the Amazonian wet season (AMAZE-08). Atmos. Chem. Phys. 15, 3687-3701 (2015).

24. Martin, S. T. et al. An overview of the Amazonian Aerosol Characterization Experiment 2008 (AMAZE-08). Atmos. Chem. Phys. 10, 11415-11438 (2010).

25. Raes, F. Entrainment of free tropospheric aerosols as regulating mechanism form cloud condensation nuclei in the remote marine boundary layer. J. Geophys. Res. 100, 2893-2903 (1995).

26. Clarke, A. D. et al. Free troposphere as a major source of CCN for the equatoria pacific boundary layer: long-range transport and teleconnections. Atmos. Chem. Phys. 13, 7511-7529 (2013).

27. Katoshevski, D., Nenes, A. \& Seinfeld, J. H. A study of processes that govern the maintenance of aerosols in the marine boundary layer. J. Aerosol Sci. 30, 503-532 (1999)

28. Williams, E. et al. Contrasting convective regimes over the Amazon: implications for cloud electrification. J. Geophys. Res. 107, 8082 (2002).

29. Machado, L. A. T., Laurent, H. \& Lima, A. A. Diurnal march of the convection observed during TRMM-WETAMC/LBA. J. Geophys. Res. 107, 8064 (2002).

30. Carslaw, K. S. et al. Large contribution of natural aerosols to uncertainty in indirect forcing. Nature 503, 67-71 (2013).

Acknowledgements Institutional support was provided by the Central Office of the Brazilian Large Scale Biosphere Atmosphere Experiment in Amazonia (LBA), the Brazilian National Institute of Amazonian Research (INPA), the Brazilian National Institute for Space Research (INPE), Amazonas State University (UEA) and Amazonas State (SDS/CEUC/RDS-Uatumã). We acknowledge the Atmospheric Radiation Measurement (ARM) Climate Research Facility, a user facility of the United States Department of Energy (US DOE), Office of Science, sponsored by the Office of Biological and Environmental Research. Funding was obtained from the Atmospheric System Research (ASR) programme (Office of Biological and Environmental Research of US DOE, under contract DE-AC02-98CH10886), the Amazonas State Research Foundation (FAPEAM-GoAmazon), the São Paulo Research Foundation (FAPESP, project numbers 2013/50510-5, 2013/05014-0 and CHUVA 2009/15235-8), the Brazil Scientific Mobility Program (CsF/CAPES-CNPq), the Brazilian Ministry of Science, Technology, and Innovation (MCTI/FINEP contract 01.11.01248.00), the German Max Planck Society (MPG) and the German Federal Ministry of Education and Research (BMBF contract 01LB1001A). This work contains results of research conducted under the Technical/Scientific Cooperation Agreement between the National Institute for Amazonian Research, Amazonas State University, and the Max Planck Society. The work was conducted under scientific licenses 001030/2012-4, 001262/2012-2 and 00254/2013-9 of the Brazilian National Council for Scientific and Technological Development (CNPq) The opinions expressed herein are the entire responsibility of the authors and not of the participating institutions.

Author Contributions J.W., S.T.M., M.O.A., P.A., L.A.T.M. and R.A.F.S. designed the research. J.W. C.K.,H.M.J.B., J.B., S.C., X.C., F.D., J.L., F.M., D.M.-Z., C.P., M.L.P., J.S S.R.S., J.M.T. and D.Wa. carried out the measurements. J.W. led the analyses, and J.W. and S.T.M. led the writing, with major input from L.A.T.M., M.O.A., S.G., R.K., T.P. and H.M.J.B., and further input from all other authors.

Author Information Reprints and permissions information is available at www.nature.com/reprints. The authors declare no competing financial interests. Readers are welcome to comment on the online version of the paper. Correspondence and requests for materials should be addressed to J.W. (jian@bnl.gov).

Reviewer Information Nature thanks H. Coe, B. Wehner and the other anonymous reviewer(s) for their contribution to the peer review of this work. 


\section{METHODS}

GoAmazon2014/5 experiment. The GoAmazon2014/5 experiment took place from January 2014 to December $2015^{9}$, and seeks to quantify and understand how aerosols and clouds in a particularly clean background in the tropics are influenced by pollutant outflow from a large tropical city. GoAmazon2014/5 is centred in the environs of Manaus, a city with a population of two million people. Manaus is an isolated urban area in the central Amazon basin that is situated at the confluence of the two major tributaries of the Amazon River. Outside Manaus there is mostly natural forest for $1,000 \mathrm{~km}$ to $2,000 \mathrm{~km}$ in every direction. As part of GoAmazon2014/5, there were six ground stations in and around Manaus as well as research flights carried out by the G-1 aircraft of the Atmospheric Radiation Measurement Aerial Facility ${ }^{31}$ of the US Department of Energy. This work focuses on measurements under clean conditions during the wet season onboard the G-1 and at the T0a site. Some analysis was also carried out using data collected at the T3 site (Extended Data Fig. 1).

Deployment of G-1 during GoAmazon 2014/5. During GoAmazon 2014/5, G-1 was deployed in two intensive operation periods, from 22 February to 23 March 2014 and 6-25 September 2014. G-1 was stationed at the Brigadeiro Eduardo Gomes-Manaus International Airport, and 16 and 19 research flights were carried out during the two intensive operation periods, respectively. The aircraft was equipped with instruments for characterizing aerosol particles, cloud droplets and trace gas species, in addition to those for measuring solar radiation, state variables and meteorological and avionics parameters ${ }^{9,31}$. Aerosol particles were sampled through an isokinetic inlet with an upper cutoff size of approximately $5 \mu$ $\mathrm{m}$. Measurements used in this study include the submicrometre particle size spectrum ranging from $10 \mathrm{~nm}$ to $400 \mathrm{~nm}$ in diameter characterized by a fast integrated mobility spectrometer (FIMS) at a time resolution of $1 \mathrm{~Hz}$ (refs 32, 33). The relative humidity of the aerosol sample was reduced to below around 30\% using a Nafion dryer before being introduced into the FIMS; therefore, the measured size spectrum represented that of the dry aerosol particles. In addition to flow rates and electrode voltages, the sizing accuracy and the counting efficiency of the FIMS as a function of particle diameter were calibrated before and after the deployment using differential-mobility-analyser-classified particle standards following methods described in ref. 34. Flow rate checks and zero tests were performed regularly during the deployment. The total particle number concentration was measured by a condensation particle counter (CPC, TSI model 3010). The size spectrum and particle number concentration were normalized to standard temperature and pressure $(273.15 \mathrm{~K}$ and $101.325 \mathrm{kPa}$; STP).

Measurements at the T0a site. Several important trace gases, aerosol properties and meteorological parameters were continuously measured at the T0a site on two towers of $80 \mathrm{~m}$ height ${ }^{10}$ during GoAmazon 2014/5. The measurements used in this study are briefly described here. Aerosol particles were sampled above the canopy at a height of $60 \mathrm{~m}$ (above ground level) using a laminar flow through a $2.5 \mathrm{~cm}$ diameter stainless steel tube. The sampled particles were transported into aerosol instruments housed in an air-conditioned container, and the relative humidity of the samples was reduced to below $40 \%$ using silica diffusion driers. The measured aerosol properties included the particle size spectrum (ranging from $10 \mathrm{~nm}$ to $430 \mathrm{~nm}$ in particle diameter) characterized by a scanning mobility particle sizer (SMPS, TSI model 3080) and the total number concentration of particles with diameters larger than $4 \mathrm{~nm}$, measured by a CPC (model 5412, Grimm Aerosol Technik). A multi-angle absorption photometer (MAAP, Carusso/Model 5012 MAAP, Thermo Electron Group) was deployed to measure the aerosol light absorption. In the MAAP instrument, the optical absorption coefficient $(\lambda=670 \mathrm{~nm})$ of the particles collected on a filter is derived using radiative transfer calculations, which take into account multiple scattering and absorption enhancements due to reflections from the filter. A mass absorption efficiency of $6.6 \mathrm{~m}^{2} \mathrm{~g}^{-1}$ was used to convert the absorption coefficient to the equivalent black carbon (BC) mass concentration. Regular quality checks were performed with all aerosol sizing instruments and CPCs, including flow checks, zero tests and intercomparisons with ambient aerosol and monodisperse polystyrene latex spheres. The MAAP was subject to frequent intercomparisons with the other optical instruments. For example, two aethalometers and the MAAP were operated side-by-side during an intensive campaign in November/December 2014. The BC concentrations from the individual instruments agreed well. Particle size spectra, number concentrations and equivalent $\mathrm{BC}$ mass concentrations were normalized to STP.

Trace gases were sampled at five levels of 4, 24, 38, 53 and $79 \mathrm{~m}$ above ground level. The sampling inlets were constantly flushed at a flow rate of several litres per minute to avoid wall interaction within the tubing. The mixing ratio of $\mathrm{CO}$ was measured by a G1302 Picarro analyser based on the cavity ring-down spectroscopy technique. Tests with a stable gas tank showed a standard deviation of the raw data of 7 parts per billion (p.p.b.) for CO. The long-term drift of the analyser was below 4 p.p.b. $\mathrm{yr}^{-1}$ for CO. The CO measurements at the level of $53 \mathrm{~m}$, above the canopy and close to the sampling level of the aerosol measurements, were used in this analysis. Meteorological parameters were continuously monitored by a suite of standard sensors. Air temperature and relative humidity were characterized using thermohygrometers (CS215, Rotronic Measurement Solutions) at six levels ranging from $4 \mathrm{~m}$ to $81 \mathrm{~m}$, and data at $81 \mathrm{~m}$ were used to derive $\theta_{\mathrm{e}}$. Rainfall was monitored using a rain gauge (TB4, Hydrological Services) at $81 \mathrm{~m}$. A barometer (PTB101B, Vaisala) was deployed at $75 \mathrm{~m}$ to characterize atmospheric pressure.

During the wet season of 2014, the T0a site was sometimes influenced by biomass burning aerosols, from as far away as Africa, as evidenced by elevated $\mathrm{CO}$ mixing ratios and the $\mathrm{BC}$ and particle number concentrations. To examine the processes under near-natural conditions, we focused on the measurements at the T0a site from 1 March to 31 May 2014 for periods with BC concentrations less than $20 \mathrm{ng} \mathrm{m}^{-3}$, CO mixing ratios less than 130 p.p.b. and particle number concentrations less than $450 \mathrm{~cm}^{-3}$. These thresholds reflect the typical values observed during the wet season in the Amazon basin in the absence of a major influence from anthropogenic emissions and biomass burning ${ }^{3}$.

Surrogate for the impact of vertical transport of free transport air. Very few synoptic systems reach the Amazonas tropical region, and when they do they are called friagem ${ }^{35}$. This type of cold outbreak event is very rare, around two cases per year ${ }^{36}$. Therefore, the decreases in $\theta_{\mathrm{e}}$ observed at T0a were overwhelmingly due to the downdrafts that bring air with low $\theta_{\mathrm{e}}$ values from the lower-middle troposphere into the boundary layer. Equivalent potential temperature has been used as a tracer to track downdraft air in many studies ${ }^{37-41}$ and was derived from the ambient temperature, pressure and relative humidity measured at the T0a site $^{42}$. The seasonal trend of $\theta_{\mathrm{e}}$ was derived by fitting a second-order polynomial to the time series of $\theta_{e}$ from 1 March to 31 May 2014 (Extended Data Fig. 7a). The equivalent potential temperature was then detrended by subtracting the fitted seasonal trend from $\theta_{\mathrm{e}}$

Magnitudes of particle number fluxes due to precipitation scavenging and vertical transport from the free troposphere. Current knowledge is not sufficient to provide an accurate quantification of the fluxes for the individual terms of the boundary layer particle number budget, including those due to downward transport during precipitation events and various aerosol removal processes. On the other hand, the magnitude of these terms can be estimated using the following approach. The dominant sink of Amazon boundary layer aerosol is precipitation scavenging, including both scavenging of aerosol particles below cloud by rain (below-cloud scavenging) and the activation of aerosol particles into cloud droplets and their subsequent removal when rain forms (in-cloud scavenging).

During the wet season, the average concentrations of accumulation-mode and Aitken-mode particles were about $100 \mathrm{~cm}^{-3}$ and $150 \mathrm{~cm}^{-3}$, respectively. The vertical distribution of aerosol number concentration observed during the wet season was roughly constant below an altitude of around 2,500 m. Rainfall occurs on approximately 20 to 25 days per month and the duration for $80 \%$ of the precipitation events is up to $3 \mathrm{~h}$, with the intensity of the majority of events up to $15 \mathrm{~mm} \mathrm{~h}^{-1}$ (refs 43-45). In the Amazon basin, aerosol particles with diameters larger than $40-60 \mathrm{~nm}$ are activated into cloud droplets during the wet season ${ }^{46}$. Assuming an average precipitation frequency of one per day, and that $50 \%$ of the Aitken-mode particles and $80 \%$ of the accumulation-mode particles below $2,500 \mathrm{~m}$ are removed after a typical precipitation event, we estimate the particle number flux due to the precipitation scavenging as:

$$
\begin{aligned}
& (150 \times 50 \%+100 \times 80 \%) \mathrm{cm}^{-3} \times\left(\frac{10^{6} \mathrm{~cm}^{3}}{\mathrm{~m}^{3}}\right) \times(2,500 \mathrm{~m}) \times\left(1 \text { day }^{-1}\right) \\
& =3.9 \times 10^{11} \mathrm{~m}^{-2} \mathrm{day}^{-1}
\end{aligned}
$$

Vertical mass fluxes have been examined using radar wind profiler measurements at the T3 site (S.G. et al., manuscript in preparation). Substantial convective activities were observed during 1543 -h periods, among a total of 1,200 in 5 months across 2 wet seasons. For the 1543 -h periods, the average mass flux due to the downdrafts in convective cores was around $0.12 \mathrm{~kg} \mathrm{~m}^{-2} \mathrm{~s}^{-1}$ at the top of the boundary layer. The mass flux averaged over the entire wet seasons is therefore 0.12 $\times(154 / 1,200)=0.0154 \mathrm{~kg} \mathrm{~m}^{-2} \mathrm{~s}^{-1}$. Note that this probably represents a lower limit, as it does not include the downward transport in stratiform rain regions. During the wet season, the difference in the particle concentrations between the free troposphere and boundary layer observed onboard G-1 ranged from $100 \mathrm{~cm}^{-3}$ to $600 \mathrm{~cm}^{-3}$ (normalized to STP). Assuming an average concentration difference of $300 \mathrm{~cm}^{-3}$, we can estimate the influx of particles from the free troposphere due to the downward transport during precipitation events as:

$$
\begin{aligned}
& \left(300 \mathrm{~cm}^{-3}\right) \times\left(\frac{10^{6} \mathrm{~cm}^{3}}{\mathrm{~m}^{3}}\right) \times\left(\frac{0.0154 \mathrm{~kg} \mathrm{~m}^{-2} \mathrm{~s}^{-1}}{1.28 \mathrm{~kg} \mathrm{~m}^{-3}}\right) \times\left(\frac{3,600 \times 24 \mathrm{~s}}{1 \text { day }}\right) \\
& =3.1 \times 10^{11} \mathrm{~m}^{-2} \text { day }^{-1}
\end{aligned}
$$


where $1.28 \mathrm{~kg} \mathrm{~m}^{-3}$ represents the density of air at STP. These estimates are obviously very rough. Nevertheless, they are consistent with the result that the total particle number concentration essentially remains constant following the precipitation (Fig. 3), which indicates that the downward transport could largely compensate the removal of particles by precipitation on a number basis. Accurate quantification of the fluxes will require future work combining both field observations and modelling efforts.

We also note that the above fluxes are estimated as daily averages, whereas the actual processes occurring during precipitation events are rapid and sporadic During a typical precipitation event, lasting $2-3 \mathrm{~h}$ (around $10 \%$ of a one-day period), downward transport injects a sufficient amount of small particles to compensate the wet removal of particles at an average concentration of around $150 \mathrm{~cm}^{-3}$ for a layer that is approximately $2,500 \mathrm{~m}$ thick.

Data availability. The data used in this study are available at http://www.arm.gov/ campaigns/amf2014goamazon and http://lfa.if.usp.br/ftp/public/LFA_Processed_ Data/T0a_ATTO.

31. Schmid, B. et al. The DOE ARM aerial facility. Bull. Am. Meteorol. Soc. 95, 723-742 (2014).

32. Olfert, J. S., Kulkarni, P. \& Wang, J. Measuring aerosol size distributions with the fast integrated mobility spectrometer. J. Aerosol Sci. 39, 940-956 (2008).

33. Wang, J. A fast integrated mobility spectrometer with wide dynamic size range: Theoretical analysis and numerical simulation. J. Aerosol Sci. 40, 890-906 (2009).

34. Kulkarni, P. \& Wang, J. New fast integrated mobility spectrometer for real-time measurement of aerosol size distribution. II: design, calibration, and performance characterization. J. Aerosol Sci. 37, 1326-1339 (2006)

35. Marengo, J. A., Nobre, C. A. \& Culf, A. D. Climatic impacts of "friagens" in forested and deforested areas of the Amazon basin. J. Appl. Meteorol. 36, 1553-1566 (1997)
36. Brinkman, W. \& Goes-Ribeiro, M. N. Air temperatures in Central Amazonia. III vertical temperature distribution on a clearcut area and in a secondary forest near Manaus. Acta Amazon. 2, 25-29 (1972).

37. Zipser, E. J. The role of organized unsaturated convective downdrafts in the structure and rapid decay of an equatorial disturbance. J. Appl. Meteorol. 8, 799-814 (1969).

38. Betts, A. K. \& Silva Dias, M. F. Unsaturated downdraft thermodynamics in cumulonimbus. J. Atmos. Sci. 36, 1061-1071 (1979).

39. Betts, A. K. The thermodynamic transformation of the tropical subcloud layer by precipitation and downdrafts. J. Atmos. Sci. 33, 1008-1020 (1976).

40. Betts, A. K. A composite mesoscale cumulonimbus budget. J. Atmos. Sci. 30, 597-610 (1973).

41. Betts, A. K., Gatti, L. V., Cordova, A. M., Dias, M. \& Fuentes, J. D. Transport of ozone to the surface by convective downdrafts at night. J. Geophys. Res. 107, 8046 (2002).

42. Bolton, D. The computation of equivalent potential temperature. Mon. Weath Rev. 108, 1046-1053 (1980).

43. Anagnostou, E. N. \& Morales, C. A. Rainfall estimation from TOGA radar observations during LBA field campaign. J. Geophys. Res. 107, 8068 (2002).

44. Lloyd, C. R. The temporal distribution of Amazonian rainfall and its implications for forest interception. Q. J. R. Meteorol. Soc. 116, 1487-1494 (1990).

45. Buarque, D. C., de Paiva, R. C. D., Clarke, R. T. \& Mendes, C. A. B. A comparison of Amazon rainfall characteristics derived from TRMM, CMORPH and the Brazilian national rain gauge network. J. Geophys. Res. 116, D19105 (2011).

46. Roberts, M. C., Andreae, M. O., Zhou, J. C. \& Artaxo, P. Cloud condensation nuclei in the Amazon Basin: "marine" conditions over a continent? Geophys. Res. Lett. 28, 2807-2810 (2001).

47. Weber, R. J. et al. Spurious aerosol measurements when sampling from aircraft in the vicinity of clouds. J. Geophys. Res. 103, 28337-28346 (1998).

48. Giangrande, S. E. et al. A summary of convective-core vertical velocity properties using ARM UHF wind profilers in Oklahoma. J. Appl. Meteorol. Climatol. 52, 2278-2295 (2013). 


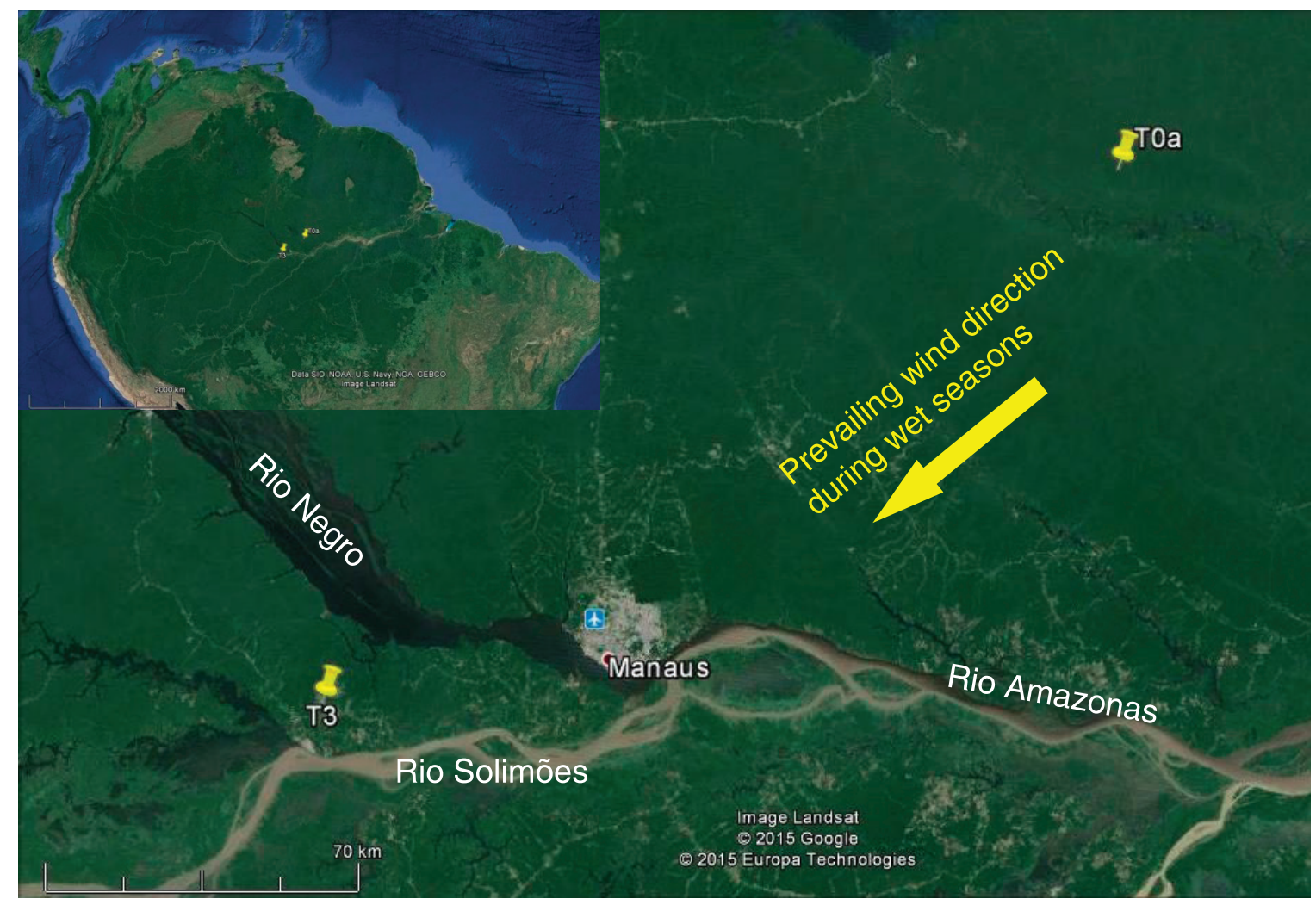

Extended Data Figure 1 | Locations of the T0a and T3 sites during GoAmazon 2014/5. Map data: Google Earth. 


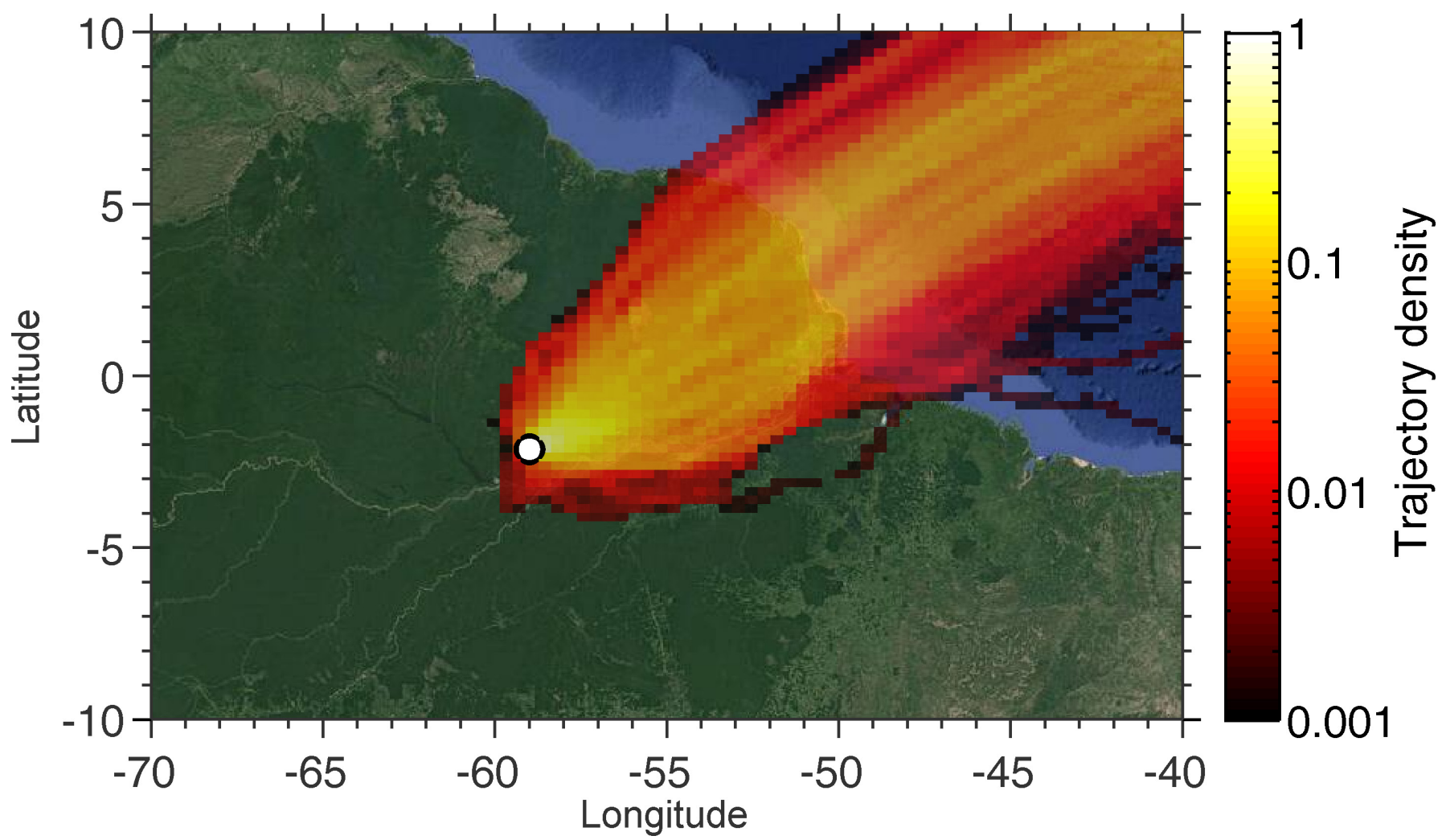

Extended Data Figure 2 Density of back trajectories of air masses arriving at the T0a site during the wet season from 1 March to 31 May 2014 . Back trajectories were originated at $100 \mathrm{~m}$ above the ground every $30 \mathrm{~min}$ using the HYSPLIT model with $0.5^{\circ}$ resolution winds from the US National Oceanic and Atmospheric Administration Global Data Assimilation System. Map data: Google. 

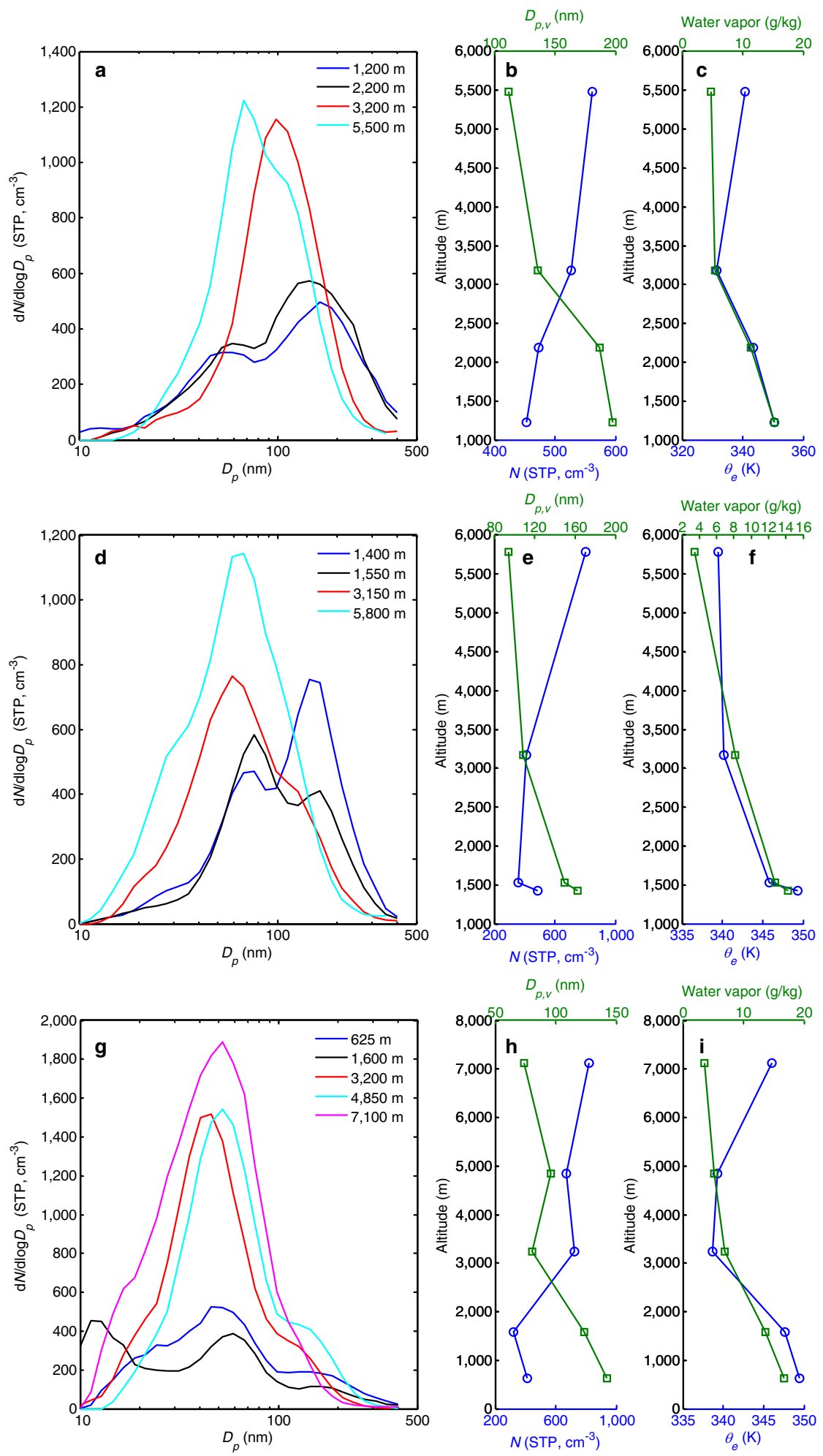

Extended Data Figure 3 | See next page for caption. 
Extended Data Figure 3 | Vertical profiles measured onboard G-1. a-i, Same as Fig. 1 for measurements made onboard G-1 at different altitudes under background conditions from 15:50-16:32 on 14 March $2014(\mathbf{a}-\mathbf{c})$, from 17:42-19:00 on 17 March 2014 (d-f) and from 14:54-17:00 on 19 March 2014 (g-i). For the flights on 14 March and 17 March the measurements are averaged over horizontal legs that were outside clouds or precipitation regions to avoid artefacts that potentially arise from the shattering of cloud droplets, ice particles or rain drops on the G-1 sampling inlet. The quantities are averages of 77, 92, 126 and 1081 -s measurements over horizontal legs that correspond to spatial scales of 8,10,15 and $11 \mathrm{~km}$ for the four altitudes shown for 14 March, and averages of 126, 288, 58 and 3601 -s measurements over horizontal legs that correspond to spatial scales of 11,27, 7 and $42 \mathrm{~km}$ for the four altitudes shown for 17 March. For the flight on 19 March 2014 there was widespread stratiform rain and ice precipitation over the G-1 sampling area. The quantities, including aerosol size spectra and particle number concentrations, are averaged over the portion of the horizontal legs with the lowest total water contents measured by a multi-element water content system (Model WCM-2000, SEA) to minimize the impact of the fragmentation of cloud droplets, rain drops and ice particles on the G-1 sampling inlet ${ }^{47}$ on particle measurements. The quantities are averages of 54, 54, 72, 90 and 1081 -s measurements over horizontal legs that correspond to spatial scales of 5, 5, 7, 10 and $13 \mathrm{~km}$ for the five altitudes ranging from $625 \mathrm{~m}$ to $7,100 \mathrm{~m}$. The average total water contents measured by the WCM-2000 for the portions of the horizontal legs were $0.007,0.01,0,0.007$ and $0.008 \mathrm{~g} \mathrm{~m}^{-3}$ at the five altitudes. The precipitation water content was derived from the drop spectrum measured by a highvolume precipitation spectrometer (HVPS, version 3 , SPEC) and the average values were $0.028,0.042,0.0043,0$ and $0.2838 \mathrm{~g} \mathrm{~m}^{-3}$ for the five altitudes ranging from $625 \mathrm{~m}$ to $7,100 \mathrm{~m}$. The nucleation-mode particles with diameters around $10 \mathrm{~nm}$ at $1,600 \mathrm{~m}$ (Fig. $2 \mathrm{~g}$ ) were probably artefacts due to the remnant impact of rain drops shattering on the G-1 inlet. 
T3 Site $1290 \mathrm{MHz}$ Profiler Z [dBZ]

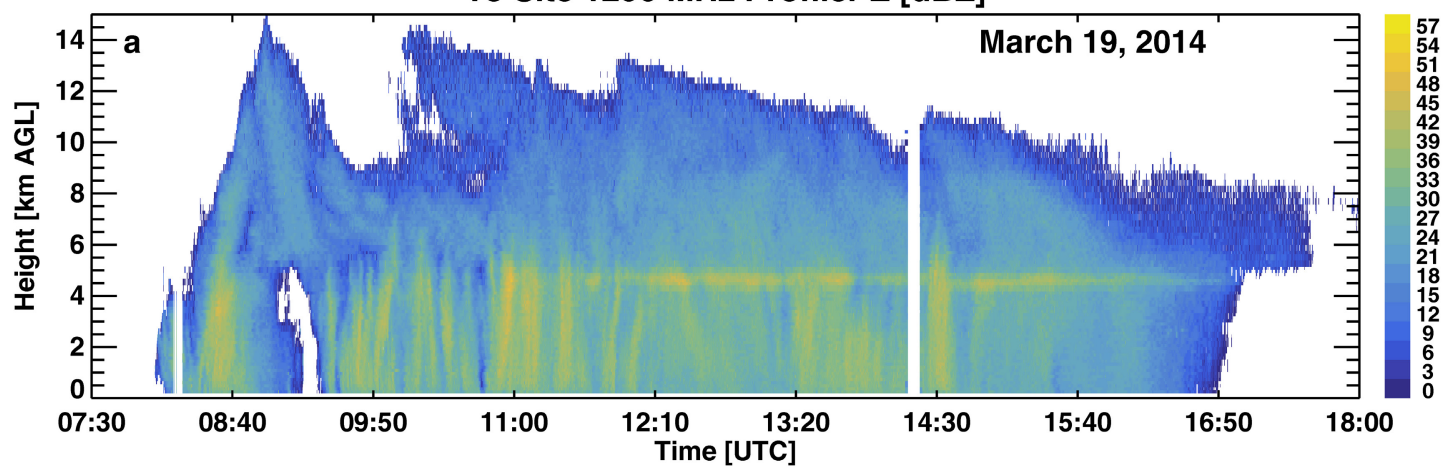

T3 Site $1290 \mathrm{MHz}$ Profiler Vertical Air Motion [m/s]

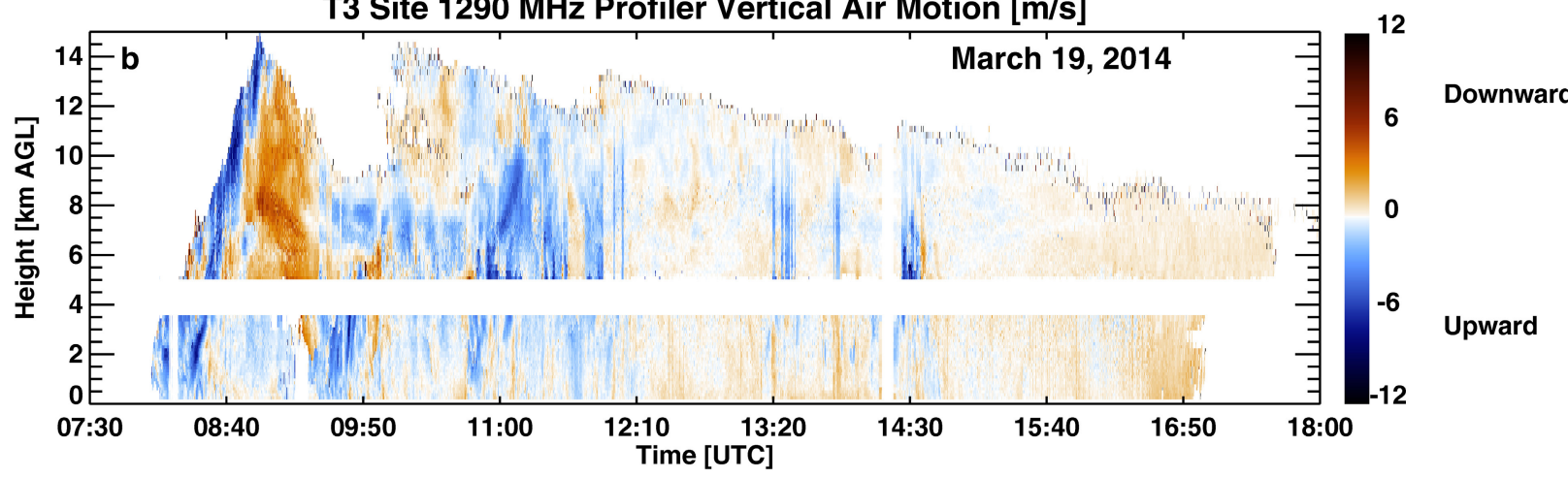

T3 Site $1290 \mathrm{MHz}$ Profiler Z [dBZ]

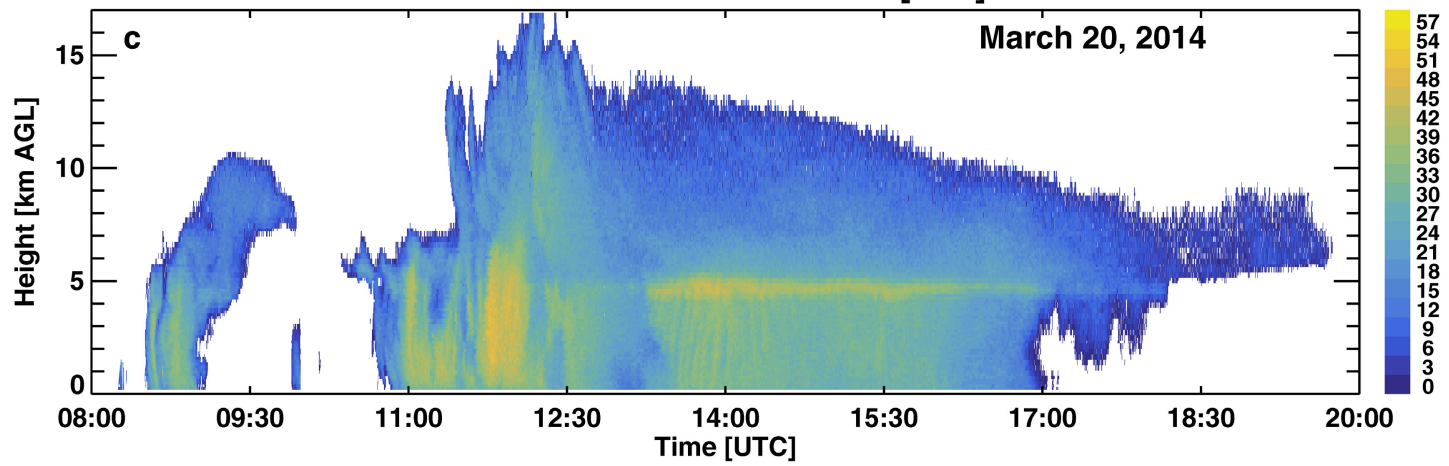

T3 Site $1290 \mathrm{MHz}$ Profiler Vertical Air Motion [m/s]

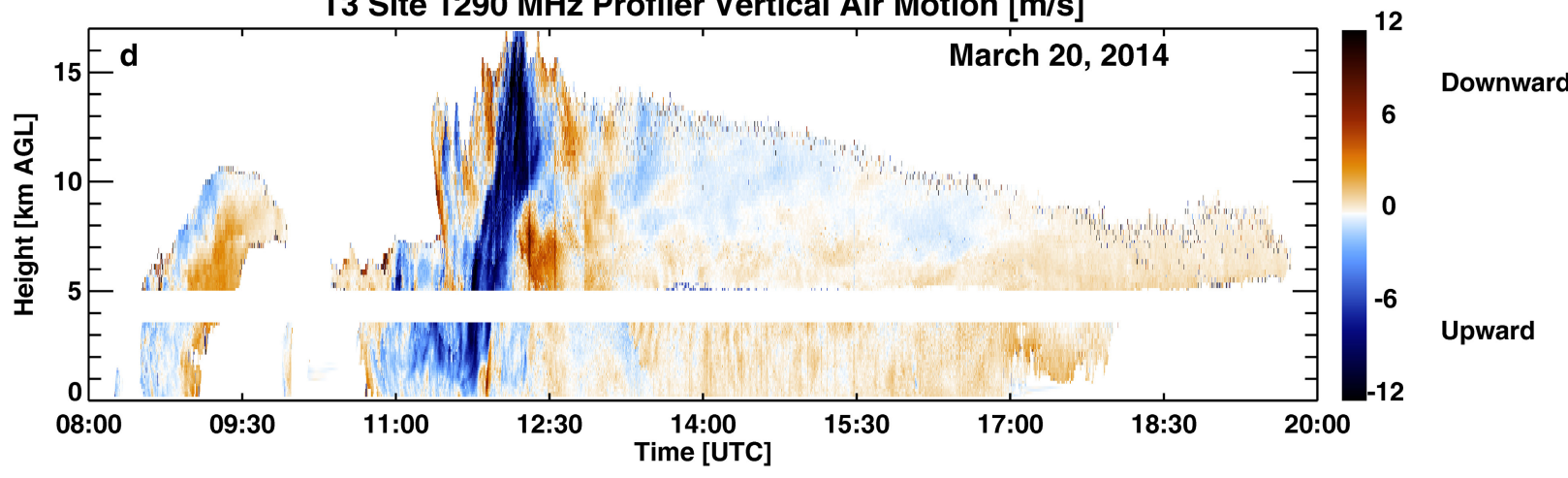

Extended Data Figure $4 \mid$ Radar reflectivity and vertical air motion. a-d, Reflectivity factor measurements (a, c) and vertical air motion estimates (b, d) from the $1,290 \mathrm{MHz}$ wind profiler deployed at the T3 site for a deep convection system on 19 March 2014 (a, b) and 20 March 2014 $(\mathbf{c}, \mathbf{d})$. Larger reflectivity factor measurements are associated with heavier precipitation. Vertical air motions were derived from profiler Doppler velocity ${ }^{48}$. Strong surface-driven convective updrafts reaching altitudes above $12 \mathrm{~km}$ were observed at 08:40 on 19 March and 11:30 on 20 March.
Adjacent to deep convective updraft cores, deep convective downdrafts from the free troposphere to the surface were often observed, as well as compensating downward motions over the extended trailing stratiform regions. Such downward motions (which have maximum velocities up to $10 \mathrm{~m} \mathrm{~s}^{-1}$ ) were consistently observed during precipitation in the wet season, and are anticipated to transport free tropospheric air with high concentrations of small particles into the boundary layer. 


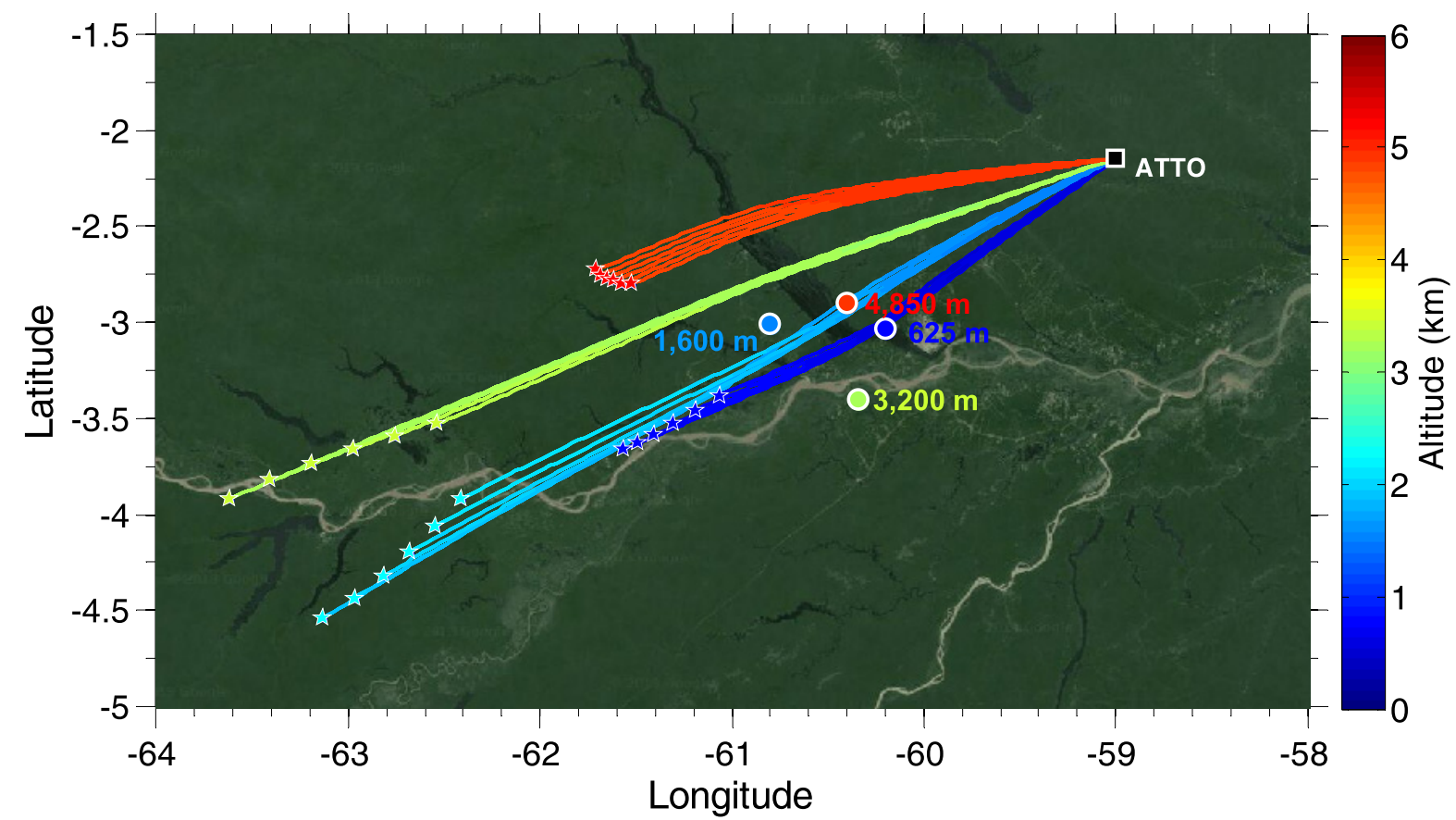

Extended Data Figure 5 | Forward trajectories of air masses starting at the T0a site. Forward trajectories starting at altitudes ranging from $625 \mathrm{~m}$ to $4,850 \mathrm{~m}$ above the T0a site around the precipitation event (that is, 04:00-06:30) on 19 March 2014 and ending at the time of G-1 sampling at the respective altitudes on the same day. The trajectories are coloured by altitude, and the end of each trajectory is indicated by a star symbol. Filled circles represent the G-1 sampling locations coloured by sampling altitude.
The average distances between the ends of the trajectories and the G-1 sampling locations are 140, 260, 300 and $140 \mathrm{~km}$ for the sampling altitudes of $625,1,600,3,200$ and $4,850 \mathrm{~m}$, respectively. This suggests that the air masses over T0a around the precipitation event reached similar locations and altitudes to those of G-1 at the time of G-1 sampling, especially at the altitudes of $625 \mathrm{~m}$ and 4,850 $\mathrm{m}$. Map data: Google. 

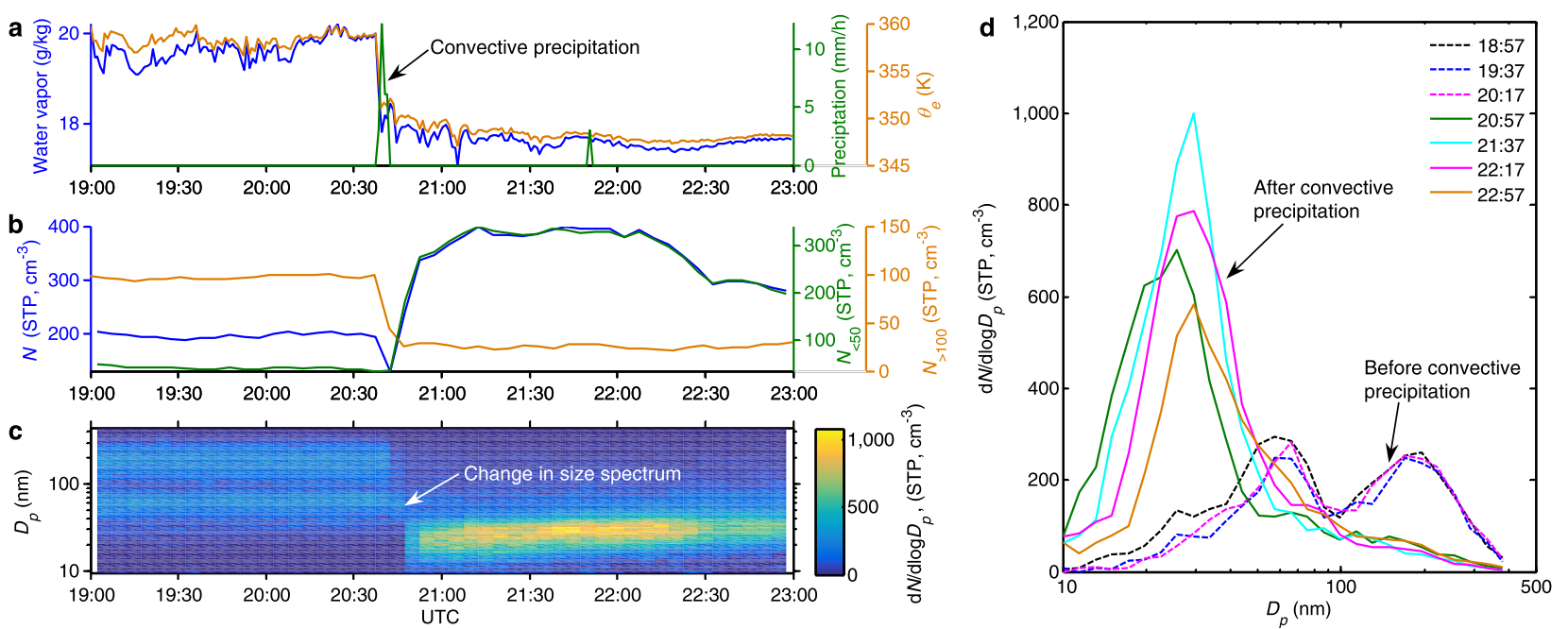

Extended Data Figure 6 | Impact of vertical transport during precipitation on boundary layer aerosol. Another example demonstrating the contribution of the vertical transport of free tropospheric small particles to the particle concentration in the atmospheric boundary layer at the $\mathrm{T} 0 \mathrm{a}$ site during a precipitation event on 4 May 2014. a, Water vapour mixing ratio, precipitation rate and $\theta_{\mathrm{e}}$. b. The total particle number concentration $(N)$, the concentration of small particles with a diameter, $D_{\mathrm{p}}$, of less than $50 \mathrm{~nm}\left(N_{<50}\right)$ and the concentration of CCN-sized particles with $D_{\mathrm{p}}$ larger than $100 \mathrm{~nm}$ $\left(N_{>100}\right)$. c, d, Particle size spectra $\left(\mathrm{d} N / \mathrm{d} \log D_{\mathrm{p}}\right)$ at ground level. 

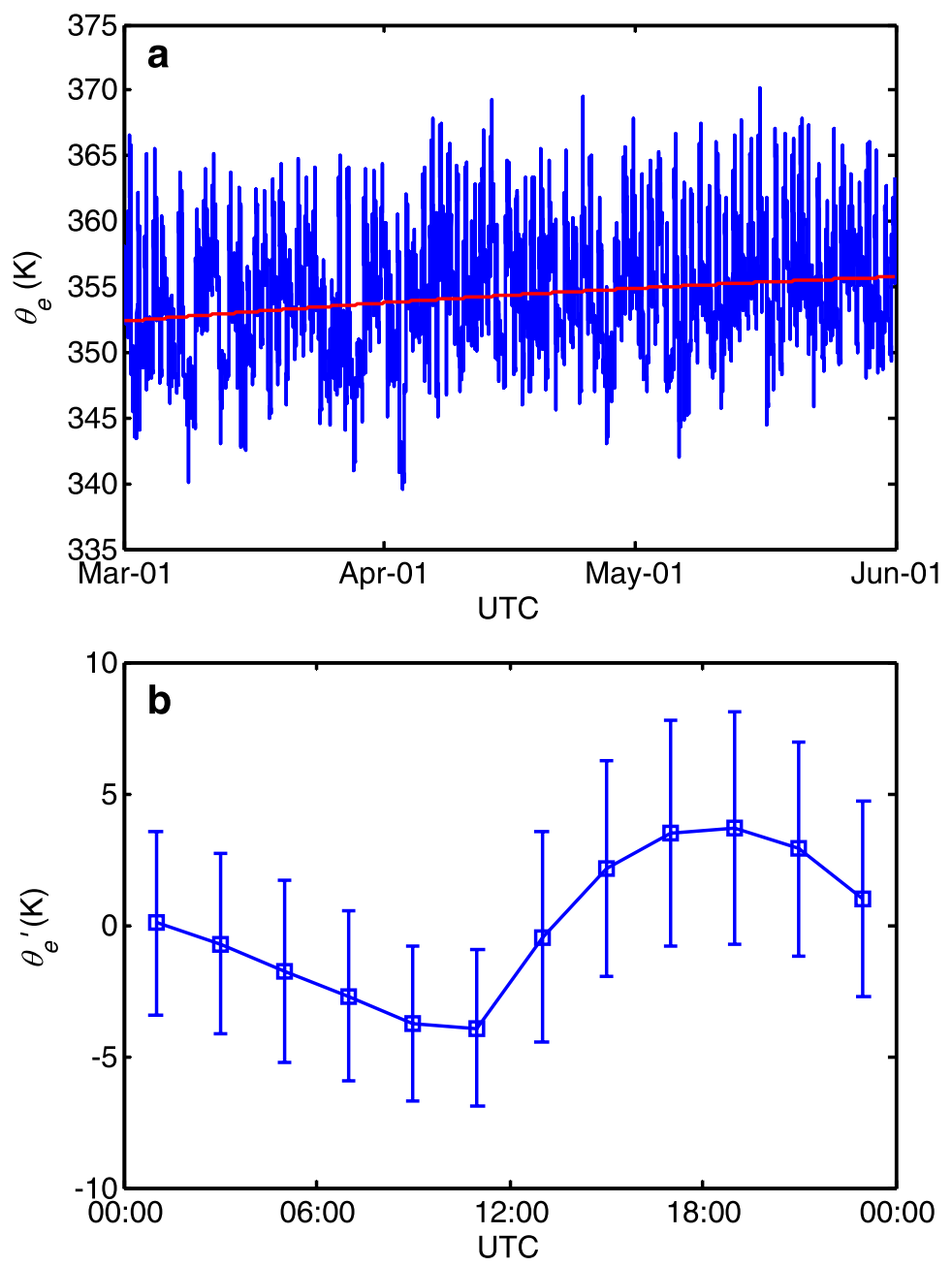

Extended Data Figure 7 | Seasonal trend and diel variation of equivalent potential temperature. a, Time series (blue line) of $\theta_{\mathrm{e}}$ derived from surface measurements at the T0a site from 1 March to 31 May 2014 and its seasonal trend (red line) fitted using a second-order polynomial. b, Diel variation of the detrended equivalent potential temperature $\left(\theta_{\mathrm{e}}^{\prime}\right)$ at the T0a site from 1 March to 31 May 2014. The error bars represent 1 s.d. of 11,040 1-min measurements. 

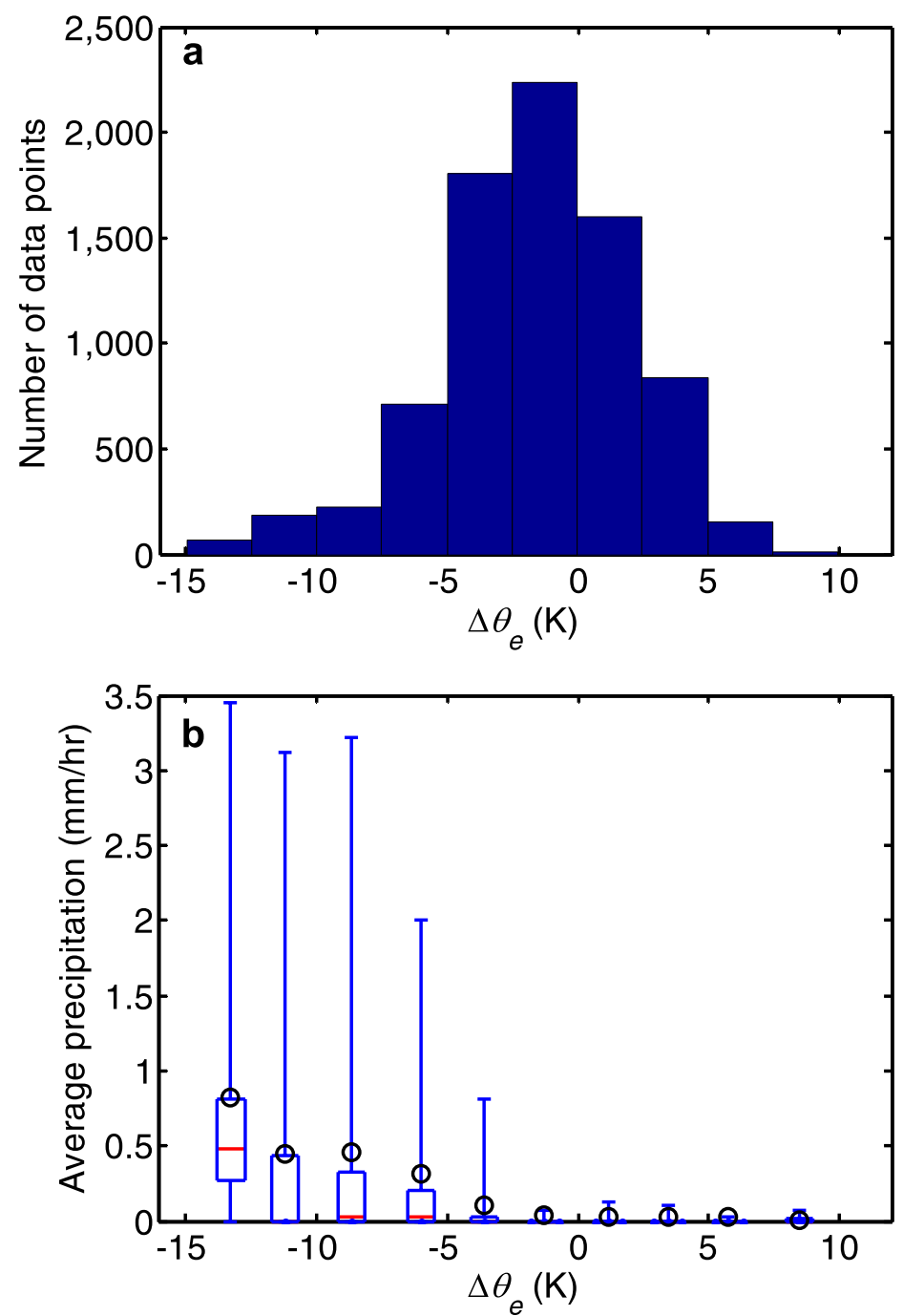

Extended Data Figure $8 \mid$ Average precipitation as a function of $\Delta \theta_{\mathrm{e}}$. a, Number of data points for each $\Delta \theta_{\mathrm{e}}$ bin. $\mathbf{b}$, Statistics of the average precipitation rate during the two hours immediately before the $\Delta \theta_{\mathrm{e}}$ measurement. The box and whisker plots are drawn for the 10th, 25th,

50th, 75th and 90th percentiles. The black circles represent the mean values. The negative $\Delta \theta_{\mathrm{e}}$ values were typically observed following precipitation, especially for values below $-5 \mathrm{~K}$. 


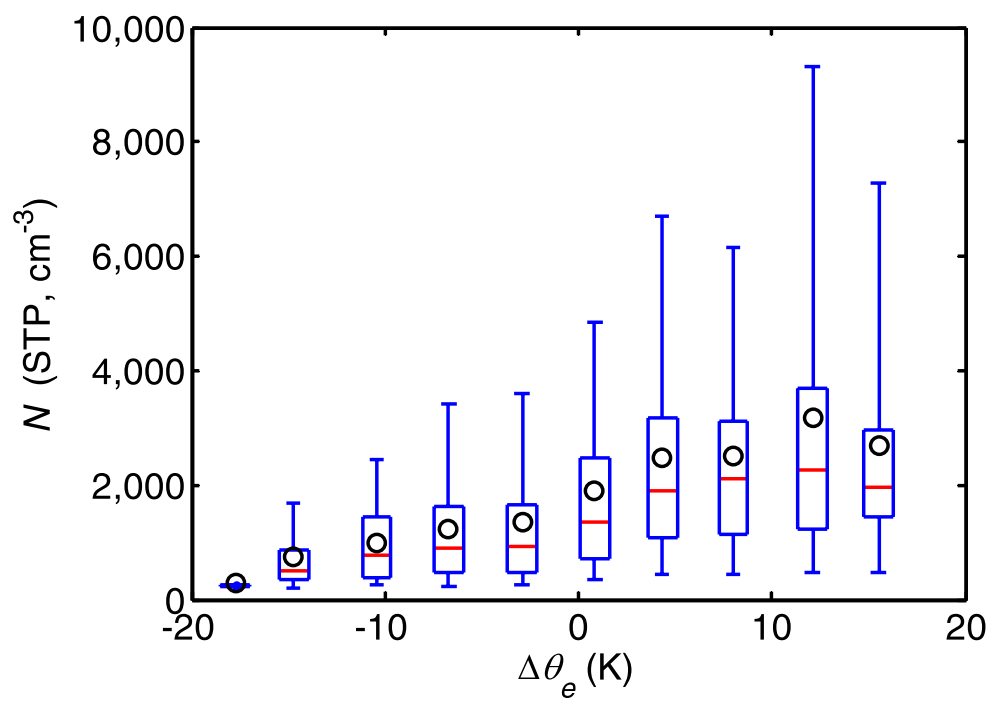

Extended Data Figure 9 | Variation of particle number concentration with $\Delta \theta_{\mathrm{e}}$ under polluted conditions. Statistics of total particle number concentration measured by a condensation particle counter (TSI, model 3010) at the T3 site from 1 March to 31 May 2014 for each $\Delta \theta_{\mathrm{e}}$ bin (that is, same as Fig. $3 \mathrm{~d}$ except that measurements were taken at the T3 site). A reduced particle number concentration was observed at low $\Delta \theta_{\mathrm{e}}$ values at the T3 site, in contrast to the almost constant particle number

concentration with $\Delta \theta_{\mathrm{e}}$ under background conditions at the T0a site. This suggests that, under polluted conditions, the vertical transport of free tropospheric aerosol cannot compensate particles removed by precipitation. The impact of vertical transport of free tropospheric particles becomes masked as anthropogenic emissions become the major source of particle number in the boundary layer under polluted conditions. 

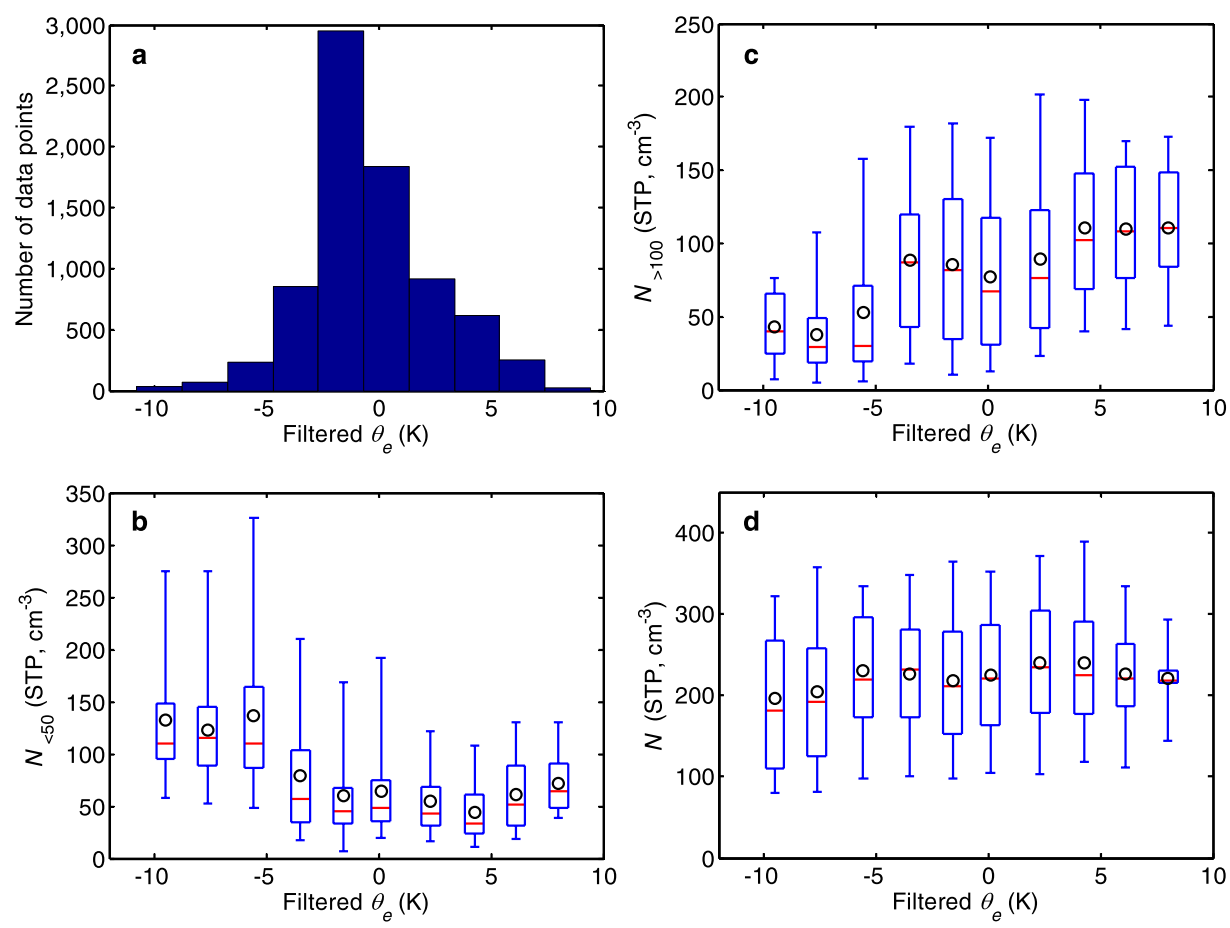

Extended Data Figure 10 | Variations in the particle number concentrations with filtered $\boldsymbol{\theta}_{\mathrm{e}}$. Same as Fig. 3 except that the analysis is based on $\theta_{\mathrm{e}}$ processed by a first-order Butterworth filter to remove the variations in $\theta_{\mathrm{e}}$ with timescales longer than $20 \mathrm{~h}$ (that is, with a frequency of less than $\left.1.2 \mathrm{~d}^{-1}\right)$. a, Number of data points for each filtered $\theta_{\mathrm{e}}$ bin. b, Statistics of small particle ( $<50 \mathrm{~nm}$ in diameter) concentrations for

each filtered $\theta_{\mathrm{e}}$ bin. c, Statistics of the CCN-sized particle ( $>100 \mathrm{~nm}$ in diameter) concentration. d, Statistics of total particle number concentration. The box and whisker plots are drawn for the 10th, 25th, 50th, 75th and 90th percentiles. The black circles represent the mean values. 